\title{
Characterization of Single Calcium Channels in Drosophila Embryonic Nerve and Muscle Cells
}

\author{
Hung-Tat Leung ${ }^{a}$ and Lou Byerly \\ Neurobiology Section, Department of Biological Sciences, University of Southern California, Los Angeles, California \\ 90089-2520
}

Voltage-activated Ca channels play a central role in synaptic transmission, control of cell excitability, and many other cellular processes. It is now clear that there are multiple types of Ca channels with various modes of modulation. Drosophila offers exceptional advantages for studying the molecular basis of the diversity and modulation of Ca channels. As a step in this study, we have characterized the single-channel Ba currents recorded from cell-attached patches on cultured embryonic Drosophila nerve and muscle cells. The voltage dependence and selectivity of the channels carrying these Ba currents identify them as $\mathrm{Ca}$ channels.

All $\mathrm{Ca}$ channels found in Drosophila neurons appear to have the same voltage dependence of activation and similar single-channel conductance, 12-17 pS (100 $\mathrm{mm} \mathrm{Ba}^{2+}$ ). However, the kinetic properties of individual $\mathrm{Ca}$ channels vary greatly. The mean open time of individual channels ranges from 2 msec to less than 0.2 msec. Some channels completely inactivate during the first half of a $90 \mathrm{msec}$ depolarization, while others are more active in the second half. Many channels open during almost every depolarization, while others open in less than $20 \%$ of the depolarizations. Channels with longer open times tend to inactivate and open during a small fraction of depolarizations. When these kinetic properties were quantified, a continuum of values was found, instead of the clustering of values that might be expected for discrete types of channels.

Muscle Ca channels form a more homogeneous class than do the neuronal $\mathrm{Ca}$ channels. The muscle $\mathrm{Ca}$ channel conductance is $18 \mathrm{pS}$. These channels do not inactivate during 90 msec depolarizations and open during a majority of depolarizations applied. Muscle $\mathrm{Ca}$ channels are similar to a subset of neuronal Ca channels.

When a purified toxin from the spider Hololena curta is applied to neurons, the number of active $\mathrm{Ca}$ channels is reduced, and those channels still active open in a small fraction of depolarization. Since channels that open in a small fraction of depolarizations tend to inactivate, these data support the hypothesis that this toxin selectively blocks noninactivating neuronal $\mathrm{Ca}$ channels. This differential toxin sensitivity and the much larger variability observed in kinetic

Received Dec. 10, 1990; revised Apr. 22, 1991; accepted May 13, 1991.

We thank Tony Defazio and Barry Johnson for help with the analysis and manuscript. This work was supported by NIH Grant NS15341 and NSF Grant BNS8903312.

Correspondence should be addressed to Lou Byerly, Department of Biological

Sciences, University of Southern California, Los Angeles, CA 90089-2520.

2 Present address: 23 Chung Hing Street, Cheung Chau, Hong Kong.

Copyright $@ 1991$ Society for Neuroscience 0270-6474/91/113047-13\$05.00/0 properties of neuronal, compared to muscle, Ca channels suggest that there are at least two types of neuronal $\mathrm{Ca}$ channels in Drosophila.

The facility with which behavioral, genetic, biochemical, and physiological studies can be applied to Drosophila provides an exceptional opportunity to understand the biological function and molecular nature of the diverse types of ion channels found in excitable cells. From only biophysical and pharmacological studies, it is not possible to determine if two channels are coded by the same or different genes. Intracellular modulation, distinct membrane properties, or altered transcriptional processing can produce diversity even in channels expressed from the same gene(s). The origin of diversity in the voltage-activated $\mathrm{K}$ channels of Drosophila is already becoming clear. Fast-inactivating $\mathrm{K}$ currents in neurons that appear biophysically to be very similar to the Shaker K currents of muscle are now known to be independent of the Shaker gene (Solc et al., 1987; Baker and Salkoff, 1990), while K currents that appear different based on inactivation can result from alternative splicing of transcripts from the same gene (Iverson et al., 1988; Timpe et al., 1988). The diversity of voltage-activated $\mathrm{Ca}$ channels is also well established (McCleskey et al., 1986; Miller, 1987; Byerly and Hagiwara, 1988). However, the molecular nature of this diversity is not understood. Only one type of Ca channel has been cloned, the dihydropyridine receptor of skeletal muscle (Tanabe et al., 1987) and cardiac muscle (Mikami et al., 1989). At present, it is not clear how closely related this $\mathrm{Ca}$ channel is to the many vertebrate and invertebrate $\mathrm{Ca}$ channels that are not specifically affected by dihydropyridines. No $\mathrm{Ca}$ channel genes have yet been identified in Drosophila. However, given the high degree of homology found between certain regions of all voltage-activated channels that have been cloned and the recent identification of spider toxins that specifically block Drosophila $\mathrm{Ca}$ currents, it seems likely that a Ca channel gene will be identified soon in Drosophila.

Although the presence of multiple types of Ca currents was first recognized in invertebrates, there has been little characterization of the diversity of invertebrate $\mathrm{Ca}$ channels at the singlechannel level. Two types of $\mathrm{Ca}$ currents were reported in the starfish egg (Hagiwara et al., 1975), polychaete egg (Fox and Krasne, 1984), a ciliate (Deitmer, 1984), and snail neurons (Mironov et al., 1984; Haydon and Man-Son-Hing, 1988), but these have not been studied at the single-channel level. Single $\mathrm{Ca}$ channels have been studied in neurons of Helix (Lux and Brown, 1984) and Aplysia (Strong et al., 1987). Only one type of Ca channel was reported in Helix neurons, while in Aplysia bag cells two types of $\mathrm{Ca}$ channels were found, which differed in 
single-channel conductance and sensitivity to protein kinase $\mathrm{C}$ activity. Recently Pelzer et al. (1989) reported multiple types of Ca channels after reconstituting Drosophila head membrane fractions in bilayers.

Our previous studies of the whole-cell Ca currents in Drosophila neurons suggest the presence of multiple types of $\mathrm{Ca}$ channels. Whole-cell $\mathrm{Ca}$ currents show inactivation and a rate of decline with dialysis (washout) that vary considerably from cell to cell (Byerly and Leung, 1988). When the neuron is dialyzed with an ATP-free internal solution, the Ca current washes out rapidly ( $50 \%$ in $5 \mathrm{~min}$ ). When ATP, dibutyryl cAMP, and theophylline are added to the internal solution, washout is eliminated in some cells but only slightly reduced in others. The rate of Ca current inactivation during depolarization and the voltage dependence of steady-state inactivation also vary greatly in different cells. While there are other plausible interpretations of these results, one interpretation is that individual neurons have different proportions of two or more types of Ca channels that have distinct inactivation properties and sensitivities to intracellular environment. Another suggestion of multiple types of Ca channels in Drosophila neurons comes from studies of toxins from the spiders Plectreurys (PLTX) and Hololena (HoTX) (Leung et al., 1989). Both toxins block Ca current at nanomolar concentrations. PLTX blocks the Ca current almost completely, while HoTX blocks only about $40 \%$ of the Ca current and primarily the noninactivating component. The differential saturating blocking effects of the two toxins would also be explained by the presence of multiple types of Ca currents with different sensitivities to the toxins.

In this study, we found that the Ca channels of Drosophila embryonic nerve and muscle cells are similar to $\mathrm{Ca}$ channels previously studied in vertebrate and molluscan neurons, in that they have fast, complicated kinetics that are poorly resolved in the recordings. All Drosophila Ca channels are activated in the same range of potentials and have similar single-channel conductance (when it can be measured). Neuronal Ca channels do differ greatly in their kinetics, but this variation is continuous, with little suggestion of discrete types of channels. However, the spider toxin HoTX selectively blocks Ca channels that exhibit a high probability of opening during each depolarization. This selective toxin sensitivity and the highly variable kinetic properties suggest that there are at least two discrete types of neuronal Ca channels in Drosophila.

\section{Materials and Methods}

Cultured cells. Cultures were made from Drosophila melanogaster (Oregon R) embryos following the method of Salvaterra et al. (1987). Cultures were maintained at $26^{\circ} \mathrm{C}$ and studied from 1 to $5 \mathrm{~d}$ following egg laying. All neuronal patches were obtained on the cell bodies of neurons of the type described by Byerly and Leung (1988). Muscle patches were obtained on myocytes and myotubes (5-10 $\mu \mathrm{m}$ width and $25-100 \mu \mathrm{m}$ length).

Patch electrodes. Both whole-cell and cell-attached patch-clamp techniques (Hamill et al., 1981) were used in this study. The application of whole-cell patch clamp to these neurons has previously been described (Byerly and Leung, 1988). For whole-cell experiments, the electrodes were pulled from $100 \mu \mathrm{l}$ VWR micropipettes (VWR, Cerritos, CA). For cell-attached patch recordings, the electrodes were pulled from thickwalled Corning 7502 glass tubing (Garner Glass, Claremont, CA). All electrodes were coated with Sylgard resin and polished to a bubble number of 3.0-5.0 (Corey and Stevens, 1983). When filled with the $\mathrm{BaCl}_{2}$ solution (described below), the resistance of the Corning 7502 electrodes was 15-25 M 2 ; the resistance of the VWR electrodes (filled with Cs-aspartate solution) was 5-15 $\mathrm{M} \Omega$.
Solutions. There were two primary solutions used in these studies: the $\mathrm{BaCl}_{2}$ solution used in the patch electrode during single-channel studies and in the bath during study of whole-cell Ba currents, and the high-K, low-Ca solution used in the bath to depolarize the cells during single-channel studies. This high-K, low-Ca solution is the internal solution used in the patch electrode during whole-cell studies of $K$ currents (Byerly and Leung, 1988); it contains $156 \mathrm{~mm} \mathrm{~K}^{+}, 139 \mathrm{~mm}$ aspartate$6 \mathrm{mM} \mathrm{Cl}^{-}, 5 \mathrm{~mm}$ EGTA, $0.5 \mathrm{~mm} \mathrm{Ca}^{2+}, 1 \mathrm{~mm} \mathrm{Mg}^{2+}$, and $10 \mathrm{~mm}$ HEPES (pH 7.3). The $\mathrm{BaCl}_{2}$ solution has $100 \mathrm{~mm} \mathrm{Ba}{ }^{2+}, 200 \mathrm{mM} \mathrm{Cl}^{-}$, and 10 mM HEPES ( $\mathrm{pH}$ 7.4). The $\mathrm{Ba}^{2+}$ in this solution was replaced with $\mathrm{Mg}^{2+}$ in experiments done to test channel selectivity. When whole-cell $\mathrm{Ba}$ currents were measured, the $\mathrm{BaCl}_{2}$ solution was outside the cell, and a Cs-aspartate solution was used in the patch electrode. This Cs-aspartate solution was identical to the high-K, low-Ca solution, except $\mathrm{Cs}^{+}$replaced $\mathrm{K}^{+}$. The Cs-aspartate solution also contained 2 mM ATP, 100 $\mu \mathrm{M}$ dibutyryl cAMP, and $2 \mathrm{mM}$ theophylline to help maintain $\mathrm{Ca}$ channel activity.

All of the single-channel Ba currents were recorded from cells bathed in a high-K, low-Ca solution. Not only did the use of this solution allow us to assume that the potential inside the neurons was close to $0 \mathrm{mV}$, but it was also essential for recording the single-channel $\mathrm{Ba}$ currents. Previously, we examined 47 cell-attached patches obtained with Bafilled electrodes on neurons in normal Drosophila salinc and found no inward currents (Byerly and Leung, 1988). In that study, the membrane potential was stepped to levels as positive as $+100 \mathrm{mV}$ relative to the resting potential; levels were separated by $20 \mathrm{mV}$. Recently, we found that cell-attached patches that exhibited no Ba currents when the cells were bathed with Drosophila saline (and stepped $80 \mathrm{mV}$ positive of the resting level) exhibited single-channel $\mathrm{Ba}$ currents when the bath was changed to the high-K, low-Ca solution (and stepped to $+20 \mathrm{mV}$ from a holding potential of $-70 \mathrm{mV}$ ). This observation would be explained if the resting potential of neurons in Drosophila saline was more negative than $-70 \mathrm{mV}$. Our failure to detect Ba currents in the previous study (Byerly and Leung, 1988) might have been due to the small number (often only one) of steps made to each potential, or to a resting potential more negative than $-90 \mathrm{mV}$.

Spider toxin. The HoTX (Bowers et al., 1987) was produced in the laboratory of Dale Branton at the University of Minnesota as described in Leung et al. (1989). Cells were exposed to approximately $100 \mathrm{~nm}$ HoTX in the high-K, low-Ca bath solution. Patches were obtained on these cells $5-60$ min following toxin application. The $\mathrm{BaCl}_{2}$ solution in the patch electrode did not contain toxin.

Equipment and software. Currents were recorded with an Axopatch 1B patch-clamp amplifier (Axon Instruments, Foster City, CA). Test protocol generation, data acquisition, and analysis were done with the pCLAMP software (version 5.05, Axon Instruments) and an Axolab-1 interface (Axon Instruments) on an IBM-AT personal computer. Some of the statistical analysis was done with SYSTAT (version 4, Systat Inc., Evanston, IL). All-point histograms and subsequent analysis of current amplitude were done with programs written in our laboratory.

Data handling. All current recordings were low-pass filtered at $1 \mathrm{kHz}$ (4-pole Bessel filter) and digitized at $200-\mu \mathrm{sec}$ intervals. Leakage and capacitive currents were determined by averaging records with no channel activity. These passive currents were subtracted from sweeps with channel activity before channel activity was analyzed. Idealized events were determined from a visual assignment of the closed- and open-state current levels. The computer then identified all crossings of the level halfway between these levels as transitions between the closed and open states. The occurrence of a channel opening and its duration were determined by these transitions. Since all computer-detected transitions were accepted, the only step of the idealization dependent on the operator was the assignment of open- and closed-state current levels. The pCLAMP program (FETCHAN) only assigned amplitudes to those openings that lasted long enough to avoid the response time of the low-pass filter. Amplitudes were calculated from the mean of the points digitized 0.7 msec after the opening transition and $0.7 \mathrm{msec}$ before the closing transitions, compared to 10 points of baseline before the opening. Thus, amplitudes were only calculated for events with open times greater than $1.4 \mathrm{msec}$.

None of the voltages given in the Results have been corrected for the junction potential that exists between the $\mathrm{BaCl}_{2}$-filled electrode tip and the high-K, low-Ca bath solution at the beginning of each experiment (before seal formation). The nominal zero potential level is taken to be the level that gives zero current at the beginning of the experiment. When measured against a $3 \mathrm{M} \mathrm{KCl}$-filled reference electrode, this junc- 


\section{Patch A}

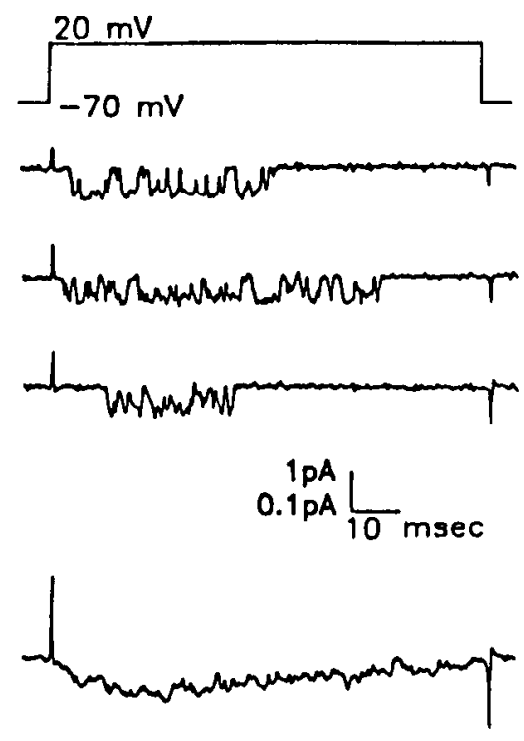

Patch B
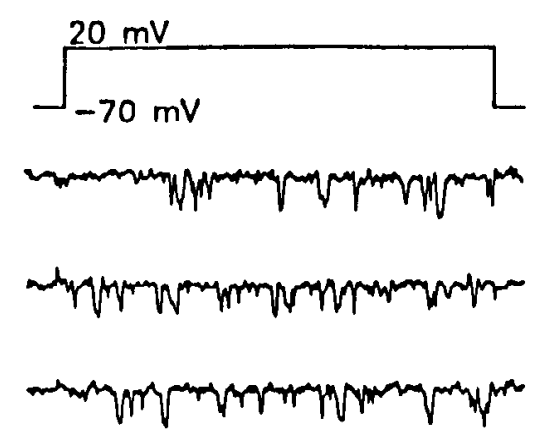

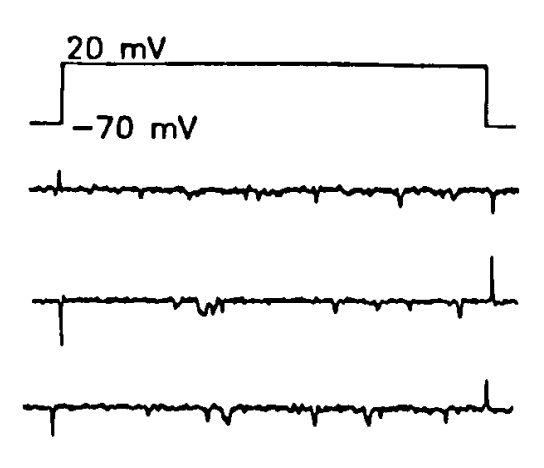

\section{Patch C}

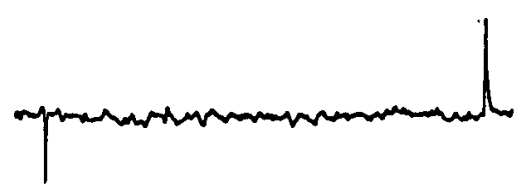

Figure 1. Three examples of single-channel Ba currents recorded from neuronal patches. The top traces indicate the time course of the depolarization applied to the patch. The middle three traces are individual current recordings during which a channel opened ( $1 \mathrm{pA}$ scale bar). Passive currents have been subtracted. The bottom traces are the ensemble current obtained by averaging 20-30 individual current recordings ( $0.1 \mathrm{pA}$ scale bar). Patch electrodes contained $\mathrm{BaCl}_{2}$ solution $\left(100 \mathrm{~mm} \mathrm{Ba}{ }^{2}\right)$, and cells were bathed in high-K, low-Ca solution. Cell numbers: $88 \mathrm{O} 03 \mathrm{C} 34$ (Patch $\left.A\right)$, $89525 \mathrm{Cl} 1$ (Patch B), 88003C01 (Patch C).

tion potential is found to be about $8 \mathrm{mV}$ (electrode positive with respect to bath). Thus, the true membrane potentials are about $8 \mathrm{mV}$ more negative than those values given in the Results. The same $-8 \mathrm{mV}$ error exists in the whole-cell Ba current experiments. Thus, the comparison of activation potentials for whole-cell and single-channel Ba currents (see Fig. 2) is not affected by neglecting these junction potentials.

\section{Results}

Identification of Ba currents through single neuronal $\mathrm{Ca}$ channels

Depolarizing voltage pulses elicited small, flickering inward currents in cell-attached patches obtained with $\mathrm{BaCl}_{2}$-filled patch electrodes on cultured Drosophila neurons. Examples of these currents recorded from three different patches are shown in Figure 1. The long quiet periods interrupted by brief bursts of inward currents suggested that these patches contained at most only a few active channels. The threc patches of Figure 1 exhibit extreme examples of the patterns of channel activity observed in these neuron cell bodies.

The voltage dependence of these inward currents supported the interpretation that they pass through $\mathrm{Ca}$ channels. Inward currents were not seen at the holding potential but were commonly observed during pulses to $+20 \mathrm{mV}$. The probability of channel opening was measured following steps to different potentials for a number of patches. As shown in Figure $2 B$, the channels opened only at potentials greater than or equal to 0 $\mathrm{mV}$. When whole-cell experiments were performed on these neurons bathed in the same $100 \mathrm{~mm} \mathrm{BaCl}$ solution that was used in the pipette for the single-channel studies, inward $\mathrm{Ba}$ currents were elicited by depolarization to $0 \mathrm{mV}$ and more positive potentials (Fig. $2 A$ ). These Ba currents are quite large and often escape from voltage control; however, the most negative voltage at which they appear indicates the membrane potential at which $\mathrm{Ca}$ channels begin to activate and agrees well with the potential at which the single-channel currents begin to appear.

The selectivity of the channels carrying the inward currents of Figure 1 agrees with that of $\mathrm{Ca}$ channels. $\mathrm{Ba}^{2+}$ must carry these inward currents since it is the only ion present on either side of the membrane that has a reversal potential more positive than $+20 \mathrm{mV}$. Although these single-channel Ba currents were seen in $36 \%$ of the patches obtained with Ba-filled electrodes, no inward single-channel currents were seen in 26 patches obtained with electrodes in which $\mathrm{Mg}^{2+}$ was substituted for $\mathrm{Ba}^{2+}$. Similar experiments conducted with electrodes containing 130 $\mathrm{mM} \mathrm{Na}{ }^{+}$and $5 \mathrm{mM} \mathrm{Ca}^{2+}$ also found no inward currents. Therefore, these channels are selective for $\mathrm{Ba}^{2+}$ over $\mathrm{Mg}^{2+}$ and $\mathrm{Na}^{+}$, as are all Ca channels (Hagiwara and Byerly, 1981). The wholecell Ca currents of these neurons (measured with $5 \mathrm{~mm}$ external $\mathrm{Ca}^{2+}$ ) were almost completely blocked by $100 \mu \mathrm{M} \mathrm{Cd}{ }^{2+}$ (Byerly and Leung, 1988). As a result of competition between $\mathrm{Cd}^{2+}$ and

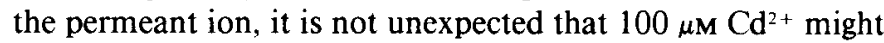
be less effective in blocking the Ca channels in the presence of a high concentration of $\mathrm{Ba}^{2+}$. We found that $100 \mu \mathrm{M} \mathrm{Cd}^{2+}$ blocked the whole-cell Ba currents $\left(100 \mathrm{mM} \mathrm{Ba}^{2+}\right)$ by $69 \%(n=4)$. When $100 \mu \mathrm{M} \mathrm{Cd^{2 }}$ was added to the $100 \mathrm{~mm}$ Ba solution in patch pipettes, 9 out of the 30 cell-attached patches (30\%) were found to have single-channel $\mathrm{Ba}$ currents, which is not significantly less than expected for patches without $\mathrm{Cd}^{2}+(36 \%)$. However, the mean open probability at $+20 \mathrm{mV}$ for the patches with $\mathrm{Cd}^{2+}$ was only 0.024 , compared to 0.060 for patches without $\mathrm{Cd}^{2+}$. This $60 \%$ reduction in open probability is consistent with the block of whole-cell Ba currents (100 $\left.\mathrm{mM} \mathrm{Ba}^{2+}\right)$ by $100 \mu \mathrm{M} \mathrm{Cd}^{2+}$, again supporting the conclusion that these single-channel $\mathrm{Ba}$ currents are passing through $\mathrm{Ca}$ channels. This action of $\mathrm{Cd}^{2+}$ to reduce the open probability of Ca channels, but not the number of active channels, agrees with the flickering type of block 
A

Ba Currents (100 $\mathrm{mM} \mathrm{Ba})$

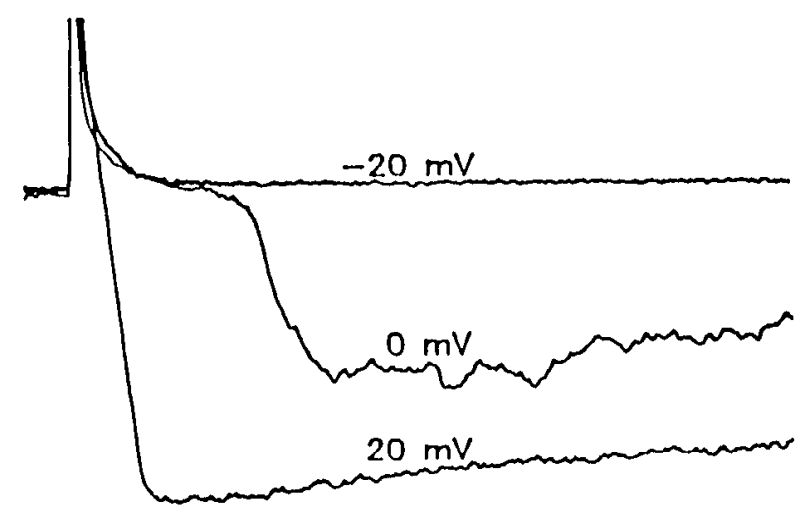

$\left.20 \mathrm{pA}\right|_{10 \mathrm{msec}}$

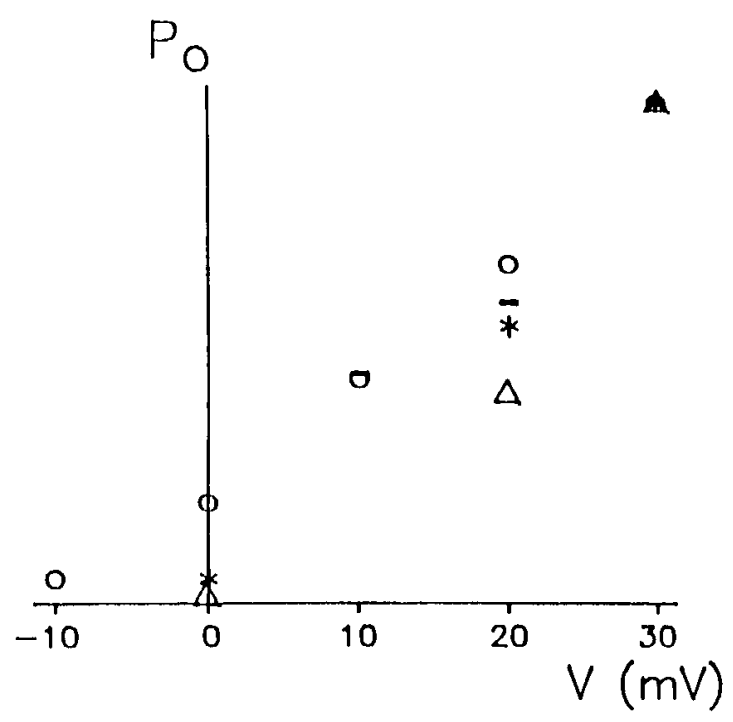

Figure 2. Voltage dependence of activation of Ba currents. $A$, Whole-cell currents recorded from a neuron during depolarizations to $-20,0$, and $20 \mathrm{mV}$. Depolarization starts at outward transient at left and continues throughout the remainder of each record; holding potential is - 70 mV. $\mathrm{BaCl}_{2}$ solution was outside, and Cs-aspartate solution was in the pipette. Passive currents were not subtracted. Cell number: $89 \mathrm{~N} 21 \mathrm{C08}$. B, Open probability for channels carrying Ba current in neuronal patches. Open probability is calculated as total duration of all current events divided by total duration of depolarizations applied. Different symbols indicate data from four different patches: data from each patch are normalized to give a constant value at $30 \mathrm{mV}$. Cell numbers: $88003 \mathrm{C01}\left({ }^{*}\right), 88003 \mathrm{C} 34(\triangle), 89406 \mathrm{C03}(-), 89513 \mathrm{C} 02(0)$.

caused by $\mathrm{Cd}^{2+}$ in mammalian L-type Ca channels (Lansman et al., 1986).

A total of 222 cell-attached patches were obtained on neurons with Ba-filled electrodes. Of these, 81 (36\%) contained singlechannel Ba currents. Only 42 patches were used in the analysis that follows. The other Ba current-containing patches were eliminated either because they contained more than one channel or as a result of poor quality of recording.

\section{Probability for opening of neuronal Ca channels}

Each $\mathrm{Ca}$ channel was characterized by repeatedly stepping the membrane potential to $+20 \mathrm{mV}$ for $90 \mathrm{msec}$ at $5 \mathrm{sec}$ intervals. $\mathrm{At}+20 \mathrm{mV}$, openings are frequent and the amplitude of unitary Ba currents is large enough to distinguish clearly openings from noise. Patches seldom lasted longer than $5 \mathrm{~min}$, so the activity of each channel was recorded only during a limited number of depolarizations. No analysis was attempted on channels to which less than 16 depolarizations were successfully applied. Figure 3 plots the number of channel openings per $90 \mathrm{msec}$ depolarization for successive depolarizations. The data are from the same three patches used in Figure 1, which were unusually long-lived patches. For Patches B and C, most depolarizations elicited at least one opening. In contrast, the channel of Patch A did not open at all in many successive depolarizations, even though it opened many times in a few depolarizations. To quantify the opening probability, we calculated two numbers for each channel: $F$, the fraction of depolarizations that elicited at least one opening, and $N$, the average number of openings per depolarization for those depolarizations that elicited at least one opening. $F$ describes the probability of opening on a time scale of seconds, while $N$ describes the probability of opening during periods of activity (on a scale of tens of milliseconds). The values of $N$ and $F$ for Patches A, B, and $\mathrm{C}$ are given in Figure 3. The product of $F$ and $N$ is the average number of openings per depolarization for all depolarizations.

As a result of random fluctuations, $F$ and $N$ values calculated for channels studied with only 16 depolarizations are not very well determined. To estimate this uncertainty, we used data from 10 channels that had been studied with a large number of depolarizations (64-160). We divided the data for each channel into successive sets of 16 depolarizations, calculating an $F$ and $N$ value for each set. The mean and SDs of these $F$ values were calculated for each patch and plotted against each other in Figure $4 A$. The error (SD) in $F$ values that are calculated from 16 depolarizations is seen to lie between 0.1 and 0.2 and agrees reasonably well with the expected error due to the counting process (smooth curve, one-fourth of square root of mean). The error in $N$ values that are calculated for 16 depolarizations is plotted in Figure $4 B$ and also agrees fairly well with the expected counting error (smooth curve, square root of mean). Of course, when $F$ and $N$ values are calculated from larger numbers of depolarization, the uncertainties are decreased.

The mean number of openings per depolarization for depolarizations that elicit at least one opening, $N$, is not related to the fraction of depolarizations that clicit openings, $F$. As can bc seen in the plot of $N$ versus $F$ values for 42 neuronal channels (Fig. 4C), there is no correlation between $N$ and $F$; the fitted slope is $0.0 \pm 3.0$ ( $\pm \mathrm{SE}$ ). This independence of $N$ and $F$ shows that the probabilities of opening on short (millisecond) and long (second) time scales are determined by distinct processes. $F$ values range from 0.06 to 0.88 , with a mean of $0.51 ; N$ values range from 2 to 22 , with a mean of 9.6. The number of depolarizations for which activity was recorded is represented in Figure $4 C$ by the area of the circle plotted for each channel. The data were weighted by the square root of the number of depolarizations in the linear regression. 


\section{Open times of neuronal Ca channels}

Drosophila Ca channels remain open for only short times, typically less than a millisecond, but certain channels exhibit consistently longer open times than others. Figure 5 shows histograms of the open time $\left(T_{o}\right)$ for Patches $\mathrm{A}, \mathrm{B}$, and $\mathrm{C}$. An exponential is fit to each histogram, and the time constant of the exponential, $\tau$, is used as a measure of that channel's open times, $t$-Values calculated for the 42 neuronal channels range from 0.2 to $2.2 \mathrm{msec}$, with a mean of $0.76 \mathrm{msec}$. Since the patchclamp amplifier was filtering at $1 \mathrm{kHz}$, very brief openings were missed; so the calculated $\tau$-value is larger than the channel's true mean open time, especially for channcls with small $\tau$-valucs (e.g., Patch C).

Due to the small number of openings observed for some $\mathrm{Ca}$ channels during 16 depolarizations, the $\tau$-values were not always well determined. To estimate the error in $\tau$-values calculated from just 16 depolarizations, we used the 10 channels that were studied for many depolarizations (64-160), calculating a $\tau$-value for successive sets of 16 depolarizations. In Figure $6 A$, the SD is plotted against the mean of the $\tau$-values calculated for each of the 10 channels. The error is seen to increase with the mean $\tau$ in a roughly linear manner. Thus, we conclude that $\tau$-values calculated from only 16 depolarizations have about $20 \%$ error. $\tau$-Values calculated from larger numbers of depolarizations are, of course, better determined.

Ca channels that have longer open times tend to remain silent during most depolarizations. Figure $6 B$ shows that there is a negative correlation between $\tau$ and $F$; the fitted slope is -1.6 $\pm 0.3 \mathrm{msec}$. The channels which open during most depolarizations tend to have short open times. There is a weaker, but significant, positive correlation between $N$ and $\tau$; the fitted slope is $3.4 \pm 1.1 \mathrm{msec}^{-1}$. In fitting straight lines to these scatter plots, the data were weighted by the square root of the number of depolarizations applied to each patch. Channels with longer open times tend to open more times during those depolarizations in which they do open. Patches A, B, and C illustrate these relationships (Figs. 1, 3, 5).

\section{Conductance of neuronal Ca channels}

Because of the short open times of these Ca channels and the limited frequency response of the current recordings, it is difficult to determine single-channel current amplitudes. Figure 7 shows all-point histograms for Patches A, B, and C. The major peak at zero current corresponds to the closed state of the channel, and its width indicates the noise of the recordings. The current values to the right of the major peak result from $\mathrm{Ca}$ channel openings. For Patch $\mathrm{A}$, there is a clear second peak, which gives a single-channel current amplitude of $0.70 \mathrm{pA}$. However, second peaks are not seen for Patches B and C. If open-state amplitudes are calculated only for long-duration, idealized events (using pcLAMP program; see Materials and Methods and Fig. 9A), then single-channel "event" amplitudes of $0.70 \pm 0.09 \mathrm{pA}$ and $0.69 \pm 0.13 \mathrm{pA}$ are calculated for Patches $A$ and $B$, respectively (thick arrows in Fig. 7). However, no event recorded from $P$ atch $C$ is long enough to calculate a singlechannel amplitude, and the amplitude calculated for Patch B is determined by a disturbingly small number of events.

In order to determine the single-channel amplitude for patches in a manner that did not require identification of events, an "all-point" amplitude was calculated dircctly from the all-point histogram. This was done by subtracting $0.26 \mathrm{pA}$ from each

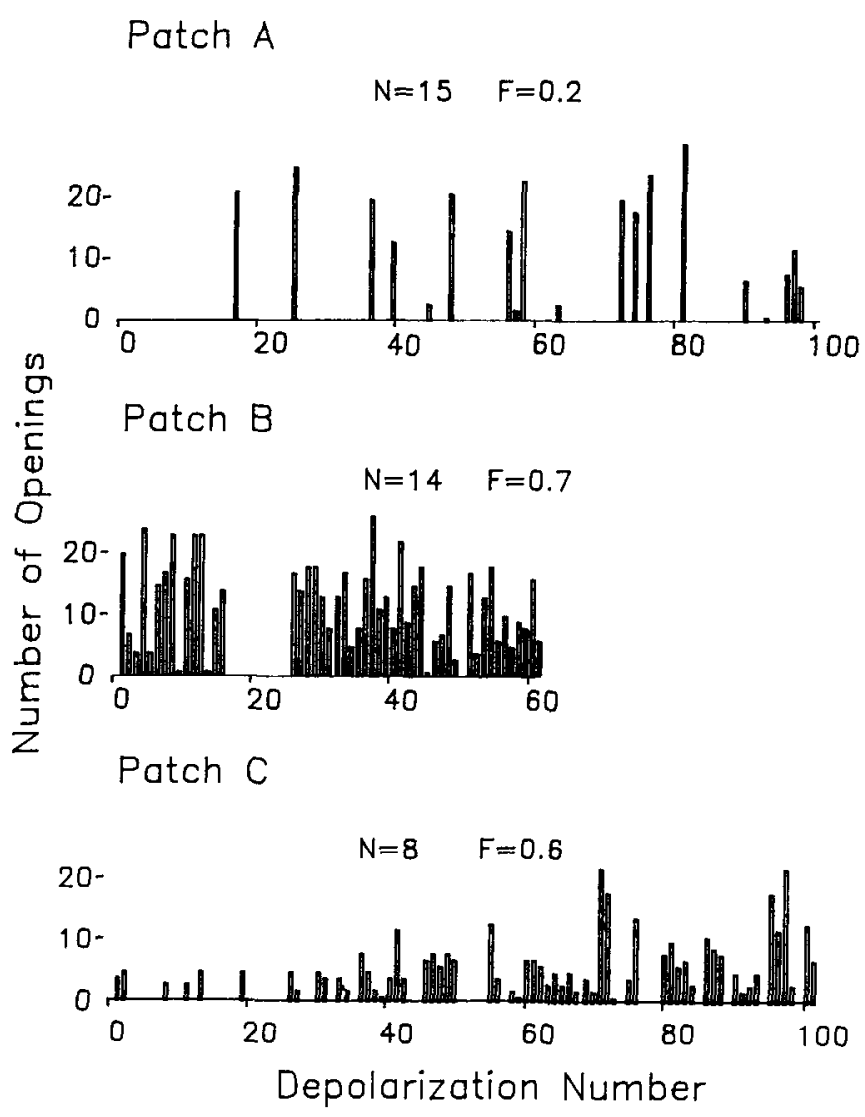

Figure 3. Variation in number of $\mathrm{Ca}$ channel openings per depolarization as seen from many repetitions of the same depolarization. The patch potential is stepped from a holding potential of -70 to $+20 \mathrm{mV}$ for $90 \mathrm{msec}$ at $5 \mathrm{sec}$ intervals. Data are taken from the same three patches from which the data of Figure 1 are taken. Above the data for each patch values are given for $N$, the average number of openings per depolarization for those depolarizations with openings, and $F$, the fraction of depolarizations that elicited openings.

histogram's "intercept current," the current at which a straight line fitted to the right-hand edge of the histogram intercepted the current axis. For those patches (like Patch A) that had a clear second peak, this intercept current was found to lie 0.26 $\pm 0.08 \mathrm{pA}$ (mean $\pm \mathrm{SD} ; n=6$ ) above the midpoint of the second peak. As can be seen in Figures 7 and $8 A$, the all-point amplitude (thin arrows in Fig. 7) agrees fairly well with the event amplitude for those patches where both amplitudes were determined, although the all-point amplitude tends to be slightly larger than the event amplitude.

All the amplitude data are consistent with the conclusion that all neuronal $\mathrm{Ca}$ channels have the same conductance (carrying about $0.7 \mathrm{pA}$ of $\mathrm{Ba}$ current at $+20 \mathrm{mV}$ ). For channels with $\tau$-values greater than $1.0 \mathrm{msec}$, both all-point amplitudes and event amplitudes are very close to $0.7 \mathrm{pA}$ (range, $0.67-0.76 \mathrm{pA}$; Fig. $8 B$ ). Both determinations of amplitude become less reliable as $\tau$ decreases. Thus, even if there is only one conductance, it is not surprising that amplitudes range from 0.36 to $0.90 \mathrm{pA}$ for channels with $\tau$-values less than $0.5 \mathrm{msec}$ (Fig. $8 B$ ). Of course, it is possible that there are $\mathrm{Ca}$ channels with short $\tau$-values that have different conductances, but our ability to measure current amplitudes of short duration is too poor to distinguish such conductances.

Slope conductance was calculated for five neuronal $\mathrm{Ca}$ channels. This study was attempted only with channels that had 

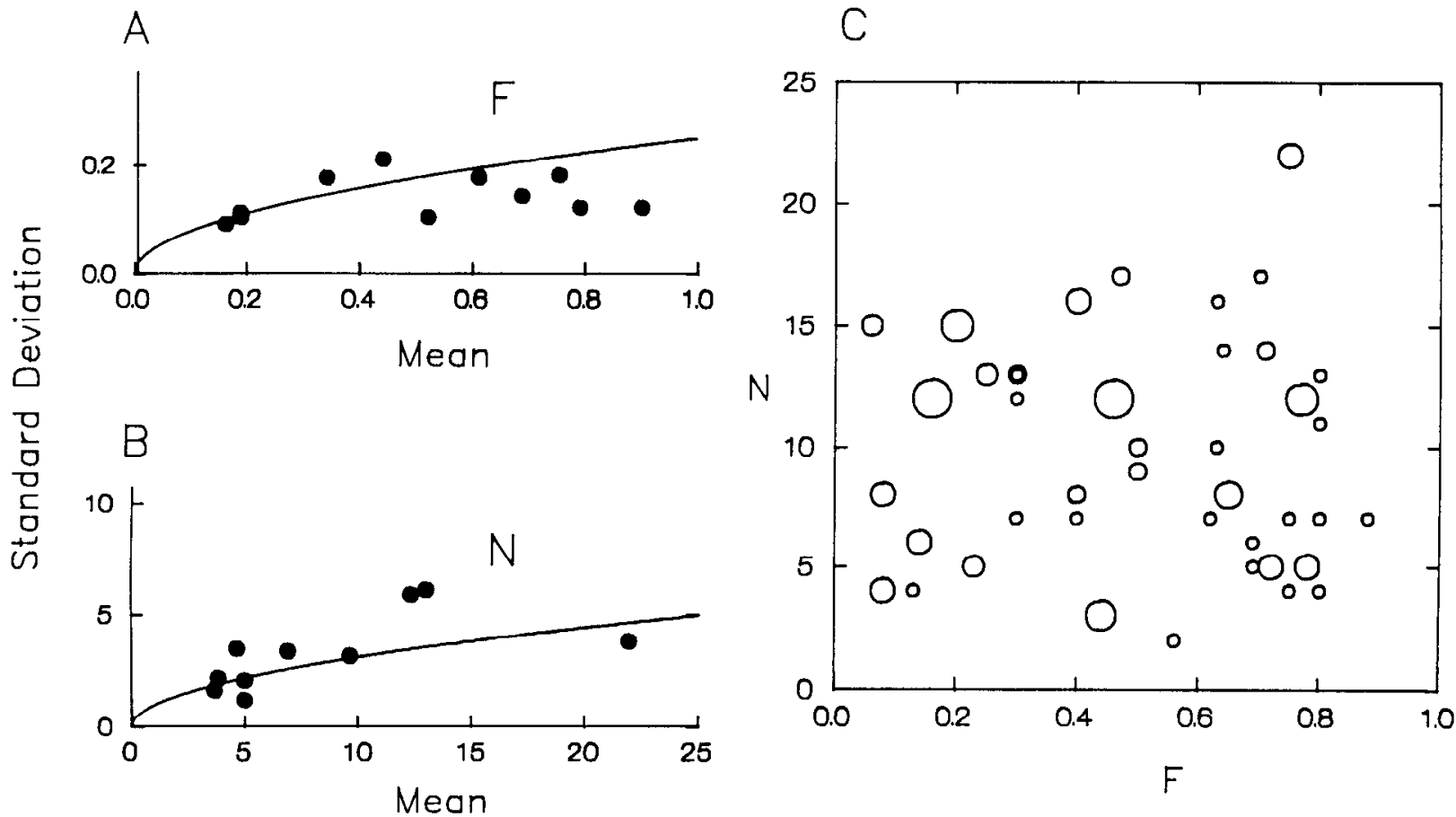

Figure 4. Distribution of $F$ and $N$ values for neuronal Ca channels. $A$ and $B$, Errors in $F$ and $N$ values that are determined from only 16 depolarizations. Ten $\mathrm{Ca}$ channels were studied for 64-160 depolarizations. The depolarizations were divided into sets of 16, and then $N$ and $F$ values were calculated for each set. The SD is plotted against the mean of each channel for the $F$ values $(A)$ and $N$ values $(B)$. The smooth curves show the deviations expected in counting randomly occurring events: one-fourth of square root of mean $(A)$ and square root of mean $(B)$. $C$, Dot plot of $N$ and $F$ values for 42 neuronal channels. The area of the circle is proportional to the number of depolarizations used to determined the $N$ and $F$ values. The uncertainty in the location of the smallest circles (16 depolarizations) is given in $A$ and $B$; the uncertainty in the location of the largest circles ( 160 depolarizations) is about one-third of the values given in $A$ and $B$.

longer open times, for which the single-channel current amplitude was well determined. Since data had to be collected for many depolarizations to at least three different potential levels, only five of the longer-lived patches provided slope conductances. As for all event amplitudes, mean amplitudes were calculated from Gaussian fits to the amplitudes of long-duration, idealized events (Fig. 9A). These amplitudes are plotted against voltage in Figure $9 B$. The slope conductance calculated for each channel ranged from 11.5 to $17.0 \mathrm{pS}$, with a mean value of 14.2 $\mathrm{pS}$ (slope of line drawn in Fig. 9B).

\section{Time course of neuronal Ca channel activity}

Ca channels are sometimes identified by their inactivation, that is, the extent to which the current decays during a maintained

$$
\text { Patch A }
$$
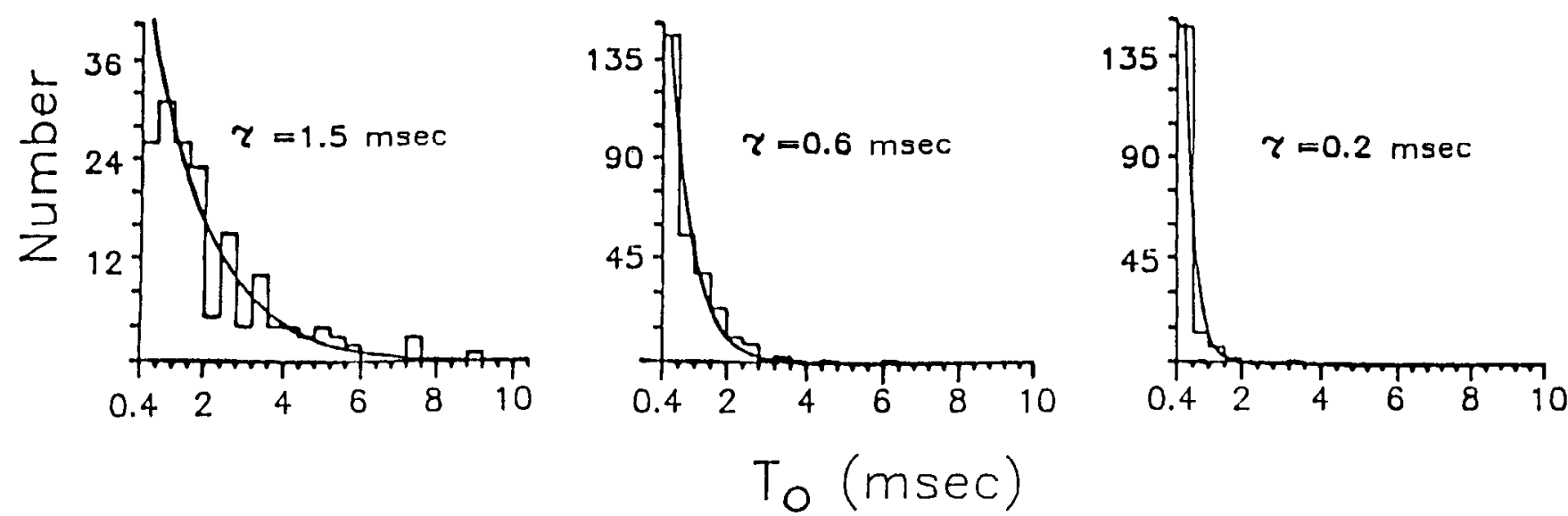

Figure 5. Distributions of open times for neuronal Ca channels. Histograms are made of the open times recorded at $20 \mathrm{mV}$ for the same three patches used in Figures 1 and 3. Smooth curves show the exponentials fitted to the histograms by pcLamp. All events with open times less than 0.4 msec have been omitted from the histograms, and the fits ignore that bin. The $\tau$-values give the time constants of these fitted curves. 


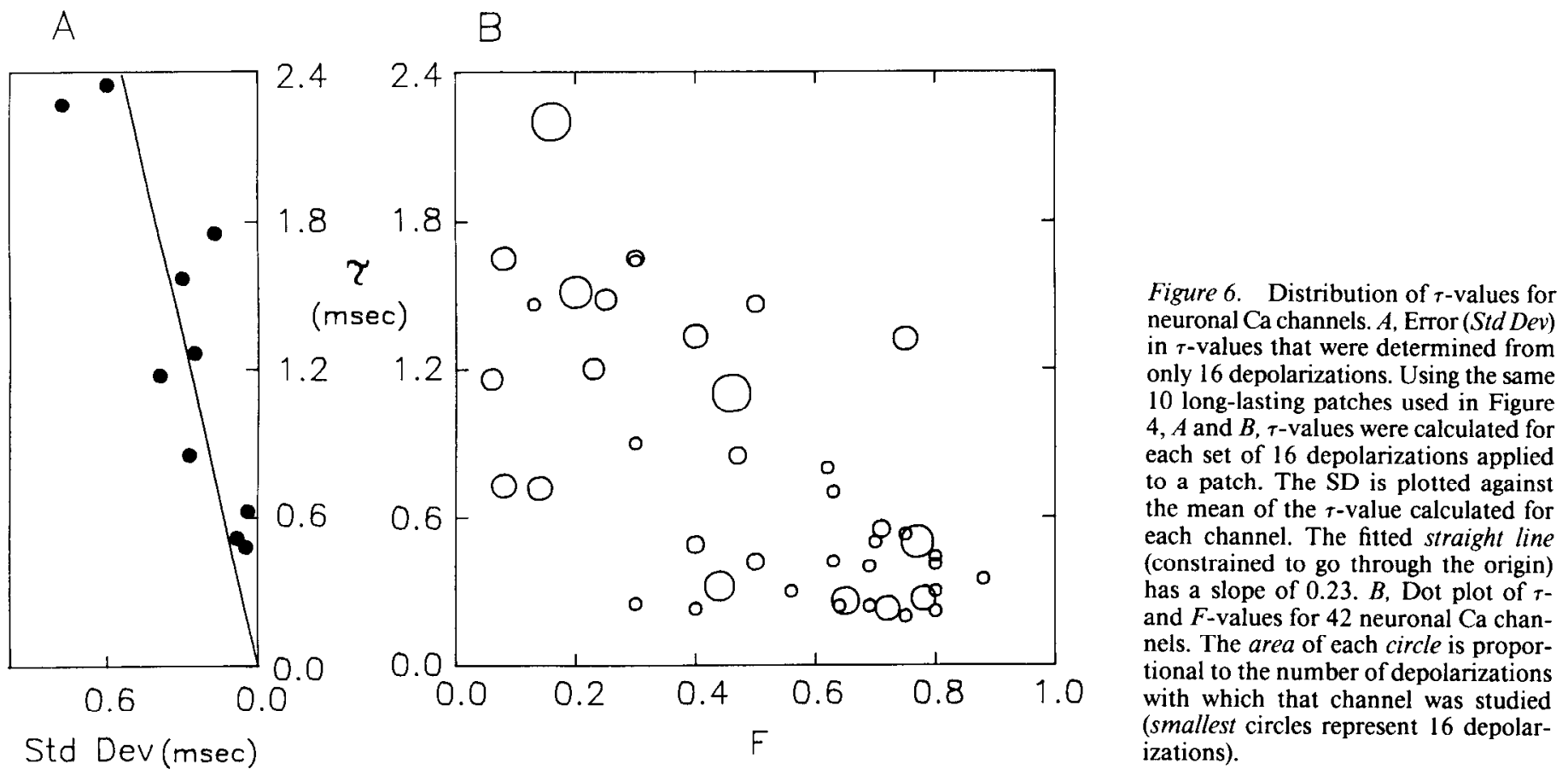

depolarization. With $\mathrm{Ba}^{2+}$ as the current carrier, whole-cell Drosophila $\mathrm{Ca}$ channel current shows a little inactivation during a $100 \mathrm{msec}$ depolarization (Fig. $2 \mathrm{~A}$ or Byerly and Leung, 1988, their Fig. 10, for Ba currents under better voltage control). To identify $\mathrm{Ca}$ channels that might be responsible for this inactivation, we calculated an inactivation parameter $I$ for each channel. $I$ is the total open time of the channel during the second half of the $90 \mathrm{msec}$ depolarization to $+20 \mathrm{mV}$ divided by the total open time during the first half. Values of $I$ less than 1.0 indicate inactivating channels. The ensemble currents of Figure
1 show that the $\mathrm{Ca}$ channel of Patch $\mathrm{A}$ inactivates, while that of Patch B does not. The ensemble current of Patch C is too small compared noise to give any information about time course. The $I$ values calculated for Patches A, B, and $\mathrm{C}$ are $0.48,1.0$, and 1.1 , respectively.

This inactivation parameter $I$ is not well determined by the data recorded during 16 depolarizations. When the data records from long-lived patches were divided into sets of 16 and $I$ calculated for each set, the $I$ values for one channel were found to differ greatly from one set of depolarizations to the next. The

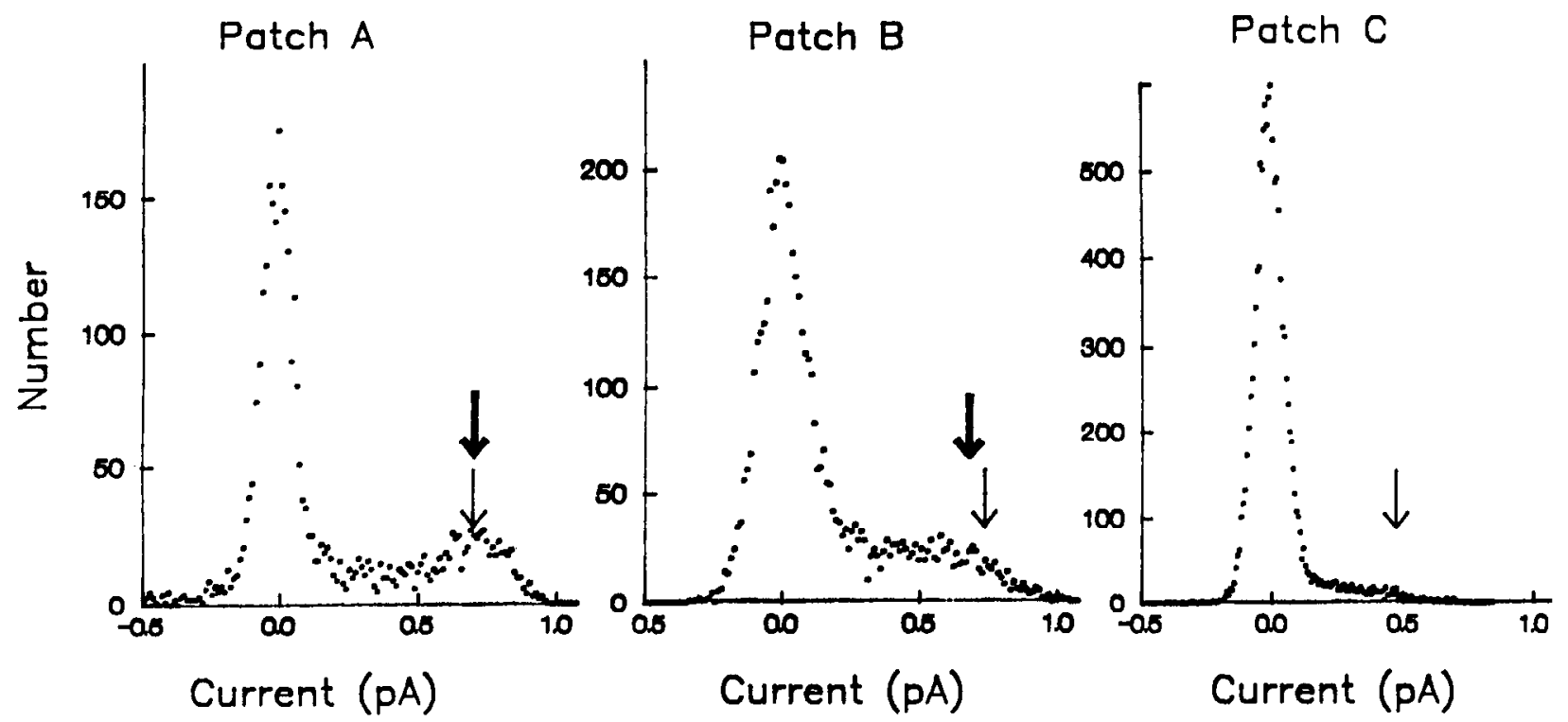

Figure 7. All-point histograms of the currents recorded from Patches $A, B$, and $C$. These data are from the same three patches for which data are presented in Figures 1, 3, and 5. All points (digitized at $200 \mu \mathrm{sec}$ intervals) were taken during a number of $90 \mathrm{msec}$ depolarizations to $20 \mathrm{mV}$, selected for stable current recording and the presence of channel openings; numbers of depolarizations used were $9($ Patch $A), 12(P a t c h B)$, and 29 (Patch $C$ ). The data from each depolarization were shifted so that the closed-state peak occurred at 0.0 pA. All-point amplitudes, calculated from these histograms as explained in the text and indicated by thin arrows, are $0.70 \mathrm{pA}$ (Patch A), $0.76 \mathrm{pA}$ (Patch B), and $0.46 \mathrm{pA}($ Patch $C)$. Event amplitudes, indicated by thick arrows, are $0.70 \mathrm{pA}($ Patch $A)$ and $0.69 \mathrm{pA}($ Patch $B)$. 

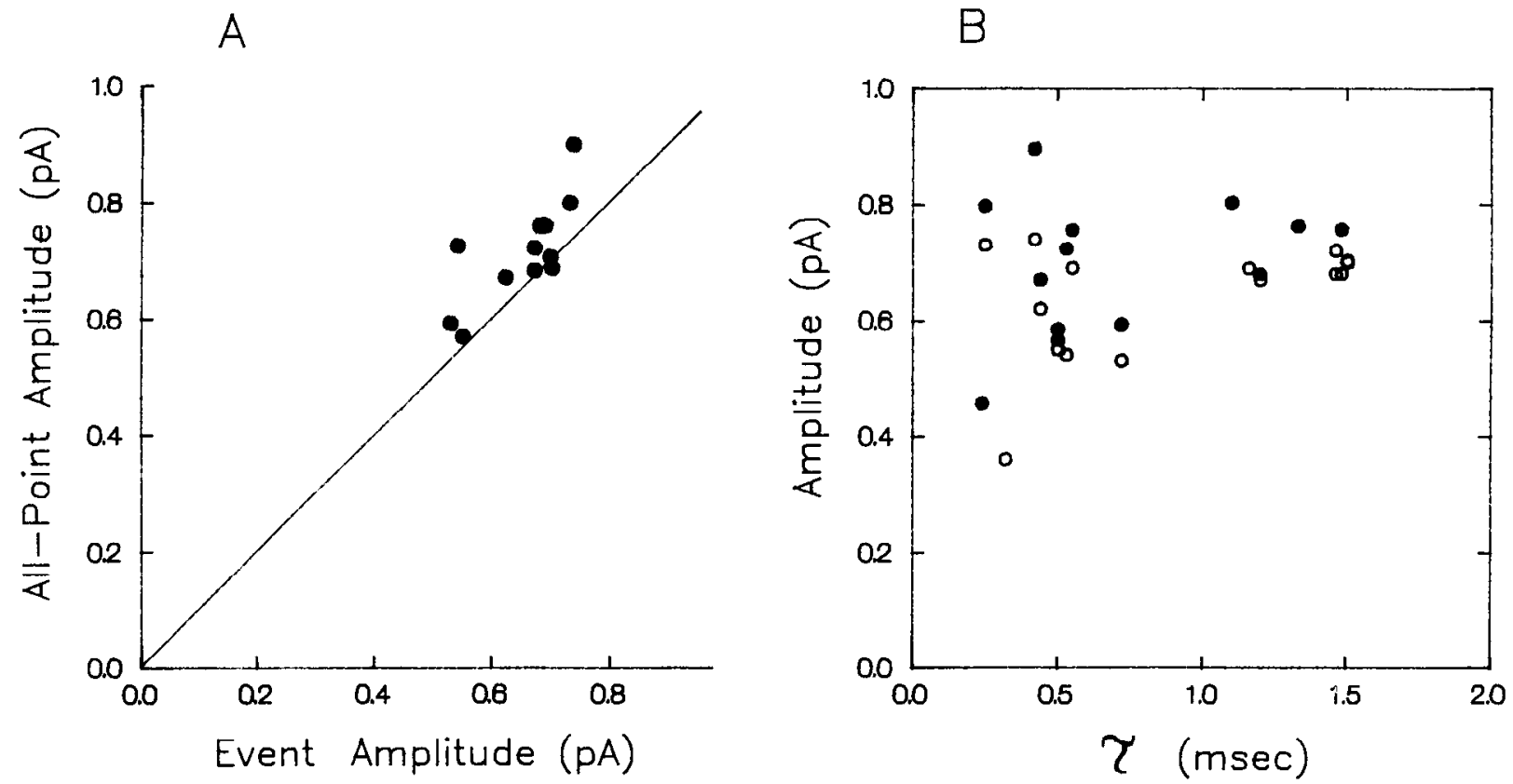

Figure 8. Comparison of neuronal Ca channel current amplitudes as determined from idealized events (event amplitudes) and from all-point histograms (all-point amplitudes). All amplitudes are obtained from data recorded at $20 \mathrm{mV}$. A, All-point amplitudes are plotted against event amplitudes for 12 channels that were amenable to both amplitude determinations. The straight line has a slope of 1 . B, All-point amplitudes ( $\bullet$ ) and event amplitudes $(O)$ are plotted against $\tau$, the time constant of the open-time histogram. The data include five event amplitudes for which all-point amplitudes were not determined, four all-point amplitudes for which event amplitudes were not determined, as well as 10 pairs of amplitudes.

SD of the $I$ values calculated for one channel increased roughly linearly with the mean of those $I$ values (Fig. $10 \mathrm{~A}$ ). Thus, we estimate that the error in an $I$ value calculated from the data of only 16 depolarizations is about $40 \%$.

Ca channels with longer open times inactivate, while channels with shorter open times are noninactivating. $I$ is plotted against $\tau$ for the 42 neuronal patches in Figure $10 B$. As before, the area of the circle plotted for each patch is proportional to the number of depolarizations applied to that channel. $I$ values range from 0 to 2.2 , with a mean of 0.8 , which fits with the inactivation of neuronal whole-cell $\mathrm{Ba}$ current. Channels with $I$ values greater than 1.0 exhibit a slow activation, instead of inactivation, during the $90 \mathrm{msec}$ pulse. When a straight line is fit to the data of Figure
$10 B$ (weighted by the square root of the number of depolarizations), the slope is $-0.38 \pm 0.09 \mathrm{msec}^{-1}$.

Although many of the neuronal $\mathrm{Ca}$ channels appear to show no inactivation during $90 \mathrm{msec}(I \geq 1.0)$, all of these channels inactivate over longer periods of time. Single-channel Ba currents are never seen in patches held at $+20 \mathrm{mV}$ for more than a few seconds. A systematic study of steady-state inactivation failed due to variability in channel activity and the short lives of most patches. For those few patches that did allow measuring the activity $(N, F, \tau)$ at $+20 \mathrm{mV}$ from two different holding potentials, a second measurement of channel activity from the original holding potential often showed more change than was measured between the two different holding potentials. Holding
Figure 9. Slope conductance of neuronal Ca channels. Amplitudes for single-channel $\mathrm{Ba}$ currents were determined by pcLAMP for idealized crents with open times greater than $1.4 \mathrm{msec}$. $A$, A mean single-channel current amplitude was determined at 10,20 , and $30 \mathrm{mV}$ by fitting a Gaussian to the histogram of amplitudes measured for idealized events at those potentials. The value determined at each potential is written to the right of the histogram and fitted Gaussian. The total numbers of events in the histogram are $17(10 \mathrm{mV})$, $69(20 \mathrm{mV})$, and $16(30 \mathrm{mV})$. Cell number: $89513 \mathrm{C} 02 . B$, Mean single-channel current amplitudes $(i)$ are plotted against polential for five different patches. The straight line is drawn with the mean slope conductance of $14.2 \mathrm{pS}$. Cell numbers: $88913 \mathrm{C07}$ (0), $88003 \mathrm{C} 34$ (O), 89419C09 $\left(^{*}\right), 89511 \mathrm{C02}$ (А), $89513 \mathrm{CO} 02(\triangle)$.

$$
A
$$
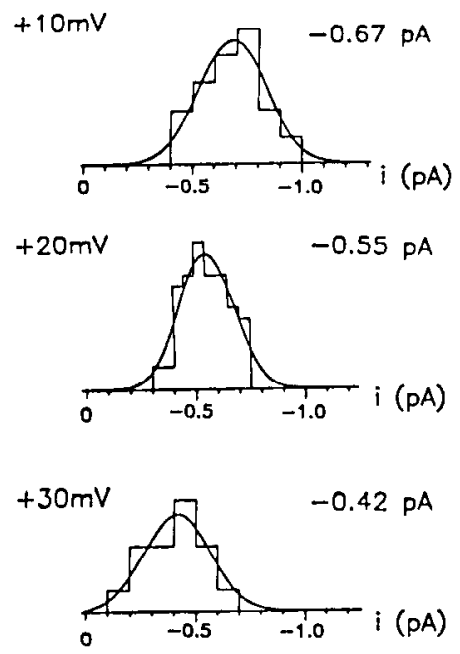

B

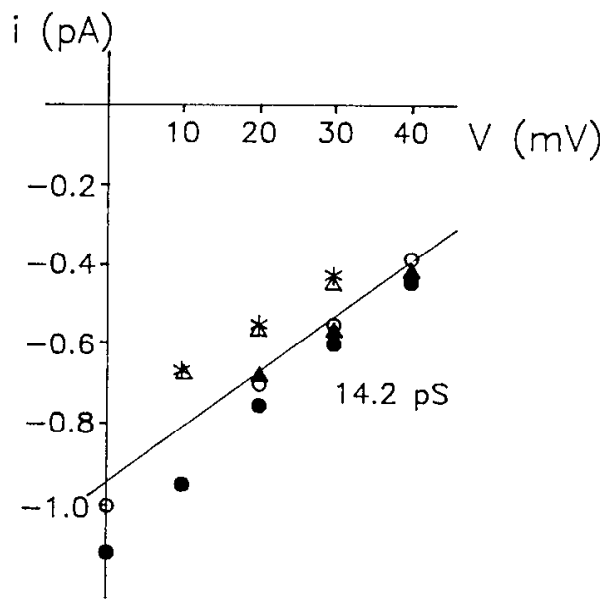



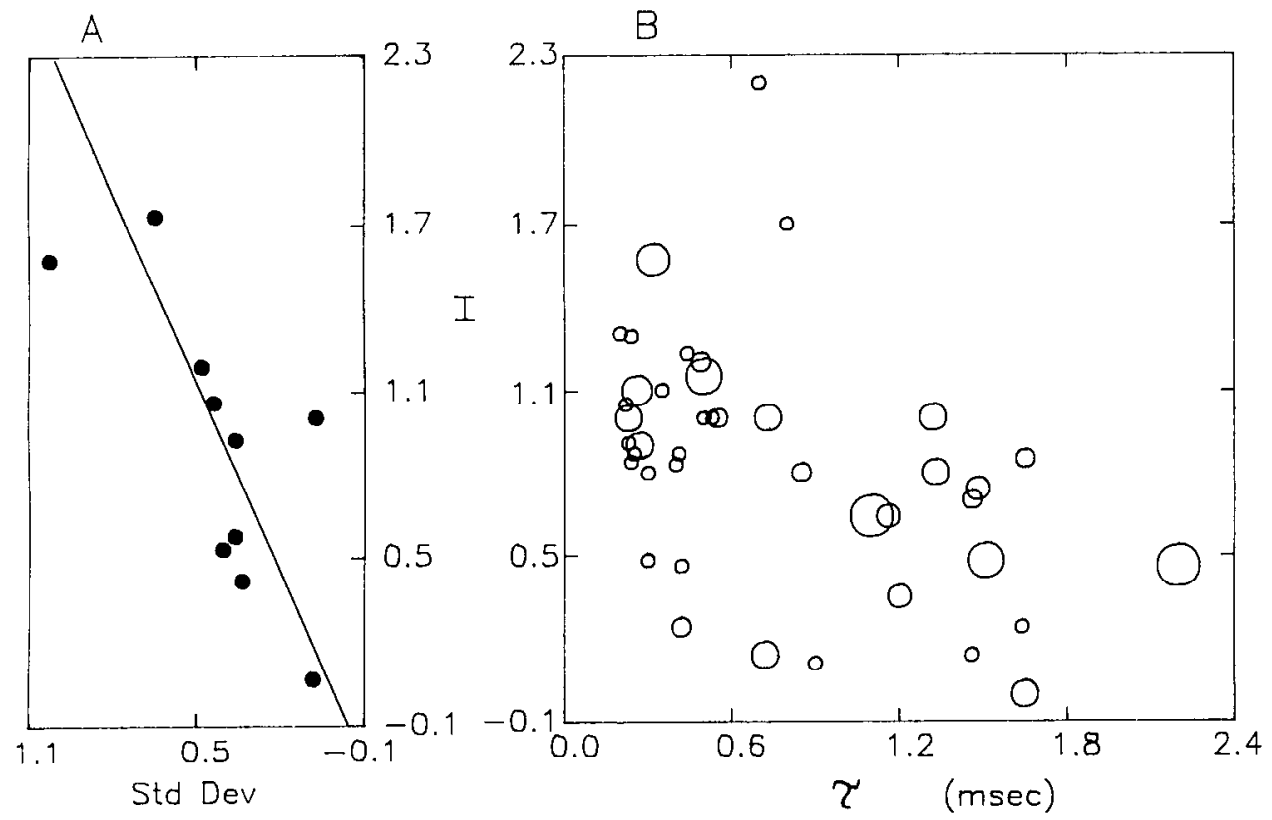

Figure 10. Distribution of $I$ values for neuronal Ca channels. $A$, Error (Std Dev) in $I$ values determined from only 16 depolarizations. Using the same 10 longlasting patches used in Figures $4, A$ and $B$, and $6, I$ values were calculated for each set of 16 depolarizations applied to a patch. The SD is plotted against the mean of the $I$ values calculated for each channel. The fitted straight line (constrained to go through the origin) has a slope of 0.44. $B$, Dot plot of $I$ and $\tau$-values for $\mathbf{4 2}$ neuronal $\mathrm{Ca}$ channels. The area of each circle is proportional to the number of depolarizations with which that channel was studied (smallest circles represent 16 depolarizations). the patch at potentials more positive than $-40 \mathrm{mV}$ greatly decreased channel activity during depolarizations to $+20 \mathrm{mV}$, usually irreversibly.

\section{Comparison of muscle Ca channels to neuronal Ca channels}

The Ca channels of cultured Drosophila myotubes were studied in the same way as were the neuronal $\mathrm{Ca}$ channels. Out of 55 patches obtained on myotubes with Ba-filled electrodes, 22 patches $(40 \%)$ contained Ba currents. Thirteen of these patches appeared to have a single Ca channel and were further analyzed. The activity of muscle Ca channels was more consistent from patch to patch than was that of neuronal channels. Figure $11 \mathrm{~A}$ shows individual current records and the ensemble average for a typical muscle channel. The muscle channel activity resembles that of the neuronal channel in Patch B of Figure 1. The voltage dependence of activation of these channels (Fig. $11 B$ ) is indistinguishable from that of the neuronal channels (Fig. 2B). Unitary currents measured for four muscle channels lie on one straight line when plotted against voltage (Fig. $11 \mathrm{C}$ ), giving a slope conductance of $18.5 \mathrm{pS}$. This is larger than the mean neuronal $\mathrm{Ca}$ channel conductance $(14.2 \mathrm{pS})$ but close to the maximum conductance ( $17 \mathrm{pS})$ measured for neuronal channels.

Muscle Ca channels do not inactivate and have intermediate duration open times. Scatter plots of $I$ versus $\tau$ and $N$ versus $F$ both for muscles (solid circles) and neurons (open circles) are presented in Figure 12. The mean $I$ value for muscle channels is 1.5 (compared to 0.8 for neuronal channels), indicating that muscle Ca channels slowly activate over $90 \mathrm{msec}$. Only one muscle channel has an $I$ value less than unity $(0.72)$; given that this channel was only studied for 16 depolarizations, this value is not significantly less than unity. The $\tau$-values for muscle channels show much less variation than do those of neuronal channels. For muscle, the mean $\tau$ is $0.46 \mathrm{msec}$ with an SD of 0.14 msec. For neurons, the mean $\tau$ is $0.76 \mathrm{msec}$ with an SD of 0.54 msec. Ca channels with longer openings, like Patch A (Fig. 1), and channels with very short openings, like Patch $\mathrm{C}$ (Fig. 1), are not found in the myotubes. While the $N$ values for muscle are similar to those of neurons, the $F$ values for muscle are never as small as they are for some neuronal channels.

\section{Selective block of neuronal Ca channels by HoTX}

HoTX, purified from the venom of the spider Hololena curta, has been shown to block specifically the Ca current of Drosophila neurons (Leung et al., 1989). HoTX only blocked about half of the total Ca current; primarily the noninactivating component was blocked. Thus, we anticipated that active $\mathrm{Ca}$ channels found in neurons treated with HoTX might have more restricted kinetic properties, since HoTX could eliminate a certain class of $\mathrm{Ca}$ channels. Since the density of $\mathrm{Ca}$ channels might vary between cultures, Ba currents in cell-attached patches were studied in both HoTX-treated neurons and untreated neurons on the same batches of cells. Of the 48 patches obtained in HoTXtreated neurons, only 12 patches (25\%) had Ba currents; 9 of these patches appeared to have only one Ca channel and were analyzed for kinetic properties. Of 22 patches obtained on untreated neurons in the same batches of cells, 11 patches $(50 \%)$ had Ba currents; 9 of these were suitable for determination of single-channel kinetic properties. In the previous studies, we found that $36 \%$ of neuronal patches (without IIoTX) had $\mathrm{Ba}$ currents. Thus, it appeared that HoTX did reduce the number of active Ca channels.

The Ca channels that survived HoTX treatment tended to exhibit more inactivation and to open in a smaller fraction of depolarizations than did the total population of neuronal $\mathrm{Ca}$ channels. Figure 13 shows a dot plot of $F$, the fraction of depolarizations that elicit channel opening, and $I$, the inactivation parameter. The active Ca channels found in HoTX-treated neurons (solid circles) cluster at smaller $F$ and $I$ values, while the Ca channels found in the control neurons (open circles) exhibit the larger range of $F$ and $I$ values previously found for neuronal Ca channels (open triangles). The $F$ value means $\pm \mathrm{SD}$ were $0.34 \pm 0.12$ for HoTX, $0.53 \pm 0.25$ for control, and $0.51 \pm$ 0.25 for the previous toxin-free neurons. The $I$ value means \pm SD were $0.65 \pm 0.39$ for HoTX, $1.02 \pm 0.50$ for control, and $0.84 \pm 0.44$ for previous toxin-free neurons. The $\tau$ and $N$ values of the HoTX-resistant channels were less clearly distinct from those of control neuronal Ca channels. None of the nine channels recorded in the presence of HoTX had $F$ values greater than 


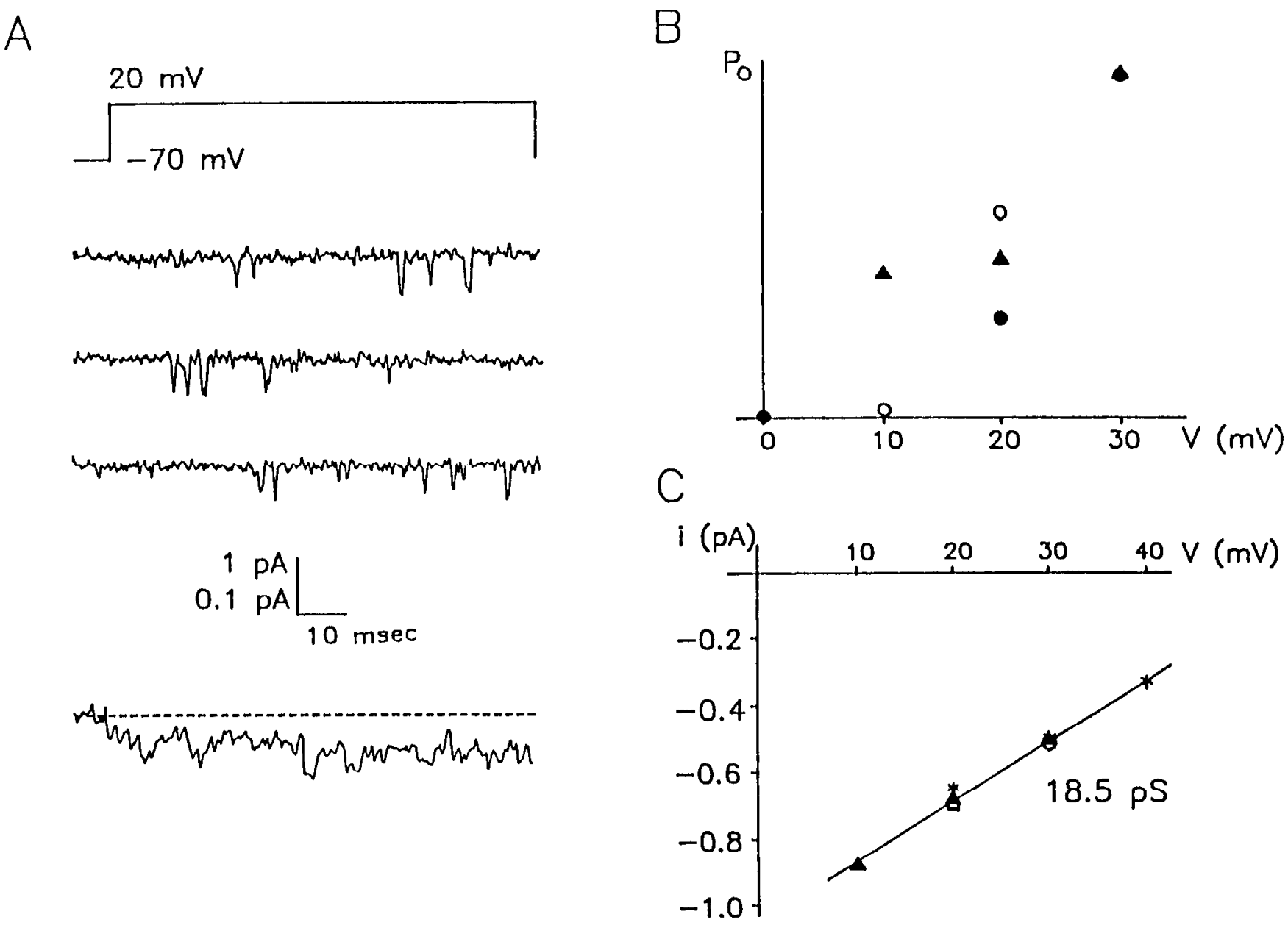

Figure 11. Muscle single-channel Ba currents. A, Individual current records (middle three traces, $1 \mathrm{pA}$ scale) and ensemble current (bottom trace, $0.1 \mathrm{pA}$ scale) for depolarizations to $20 \mathrm{mV}$ (top trace). The ensemble current is the average of 32 individual records containing channel openings. Cell number: $89417 \mathrm{C1}$ 7. B, Voltage dependence of activation. The open probability $\left(P_{o}\right)$ was measured at potentials from 0 to $30 \mathrm{mV}$ and normalized to a fixed level at $30 \mathrm{mV}$. Cell numbers: $89405 \mathrm{C} 31(0), 89406 \mathrm{C01}(\Delta), 89511 \mathrm{Cl} 7(\bullet)$. C, Slope conductance of single-channel Ba current. Mean amplitudes $(i)$ determined by Gaussian fits to the amplitudes of idealized events. The straight line has a slope of $18.5 \mathrm{pS}$. Cell numbers: $89405 \mathrm{C} 31$ (O), 89406C01 (A), 89417C01 (*), 89417C17 (-).

0.54 , while 26 of the $51(51 \%)$ channels recorded in the absence of HoTX had $F$ values greater than 0.54 . The probability of picking nine channels at random from this population and getting none with $F$ values greater than 0.54 is only $0.2 \%$. Therefore, HoTX clearly prevents the recording of $\mathrm{Ca}$ channels with larger $F$ values. A simple interpretation is that HoTX blocks Ca channels with large $F$ values, since less Ca channels are found in the presence of HoTX. A similar argument to that applied above for the $F$ values is that there is a $13 \%$ chance of getting the $I$ values recorded for the channels in Hol $\mathrm{X}$ even from the population of HoTX-free channels. We have not yet recorded from enough Ca channels in the presence of HoTX to conclude that the noninactivating $\mathrm{Ca}$ channels (channels with larger $I$ values) are selectively eliminated. However, since $F$ is positively correlated with $I$ for the HoTX-free channels (slope is $0.36 \pm$ 0.07 ) and channels with larger $F$ values are clearly eliminated by HoTX, these data certainly support the proposed hypothesis that HoTX selectively blocks noninactivating Ca channels (Leung et al., 1989).

\section{Discussion}

Ba currents carried by voltage-activated $\mathrm{Ca}$ channels are readily recorded from cell-attached patches on cultured Drosophila neu- rons and muscle cells. About $40 \%$ of the cell-attached patches were found to have Ba currents in both types of cells. This clearly refutes our previous conclusion that either Drosophila neuron Ca channels carry very small currents or that the channels are located in inaccessible parts of the membrane (Byerly and Leung, 1988). Bathing the cells in high-K, low-Ca solution was the critical step that allowed us to observe the Ca channel currents, possibly because the resting potential of the neurons is very negative in Drosophila saline (see Materials and Methods).

The analysis of Drosophila $\mathrm{Ca}$ channels presented here is at an elementary level. The short lifetime of the patches and the rapid kinetics of the channels were major obstacles to a more complete analysis. The open times of the channels were often short compared to the response time of the amplifier, making determination of single-channel current amplitudes and state transitions inaccurate. It was usually not possible to determine if a patch had one or several Ca channels, since the open probability was so low that simultaneous openings of channels could easily not occur during the limited duration of the recording. The single-channel current amplitude became too small to resolve at more positive potentials where the open probability was higher.

Drosophila neuronal $\mathrm{Ca}$ channels are not divided into types 

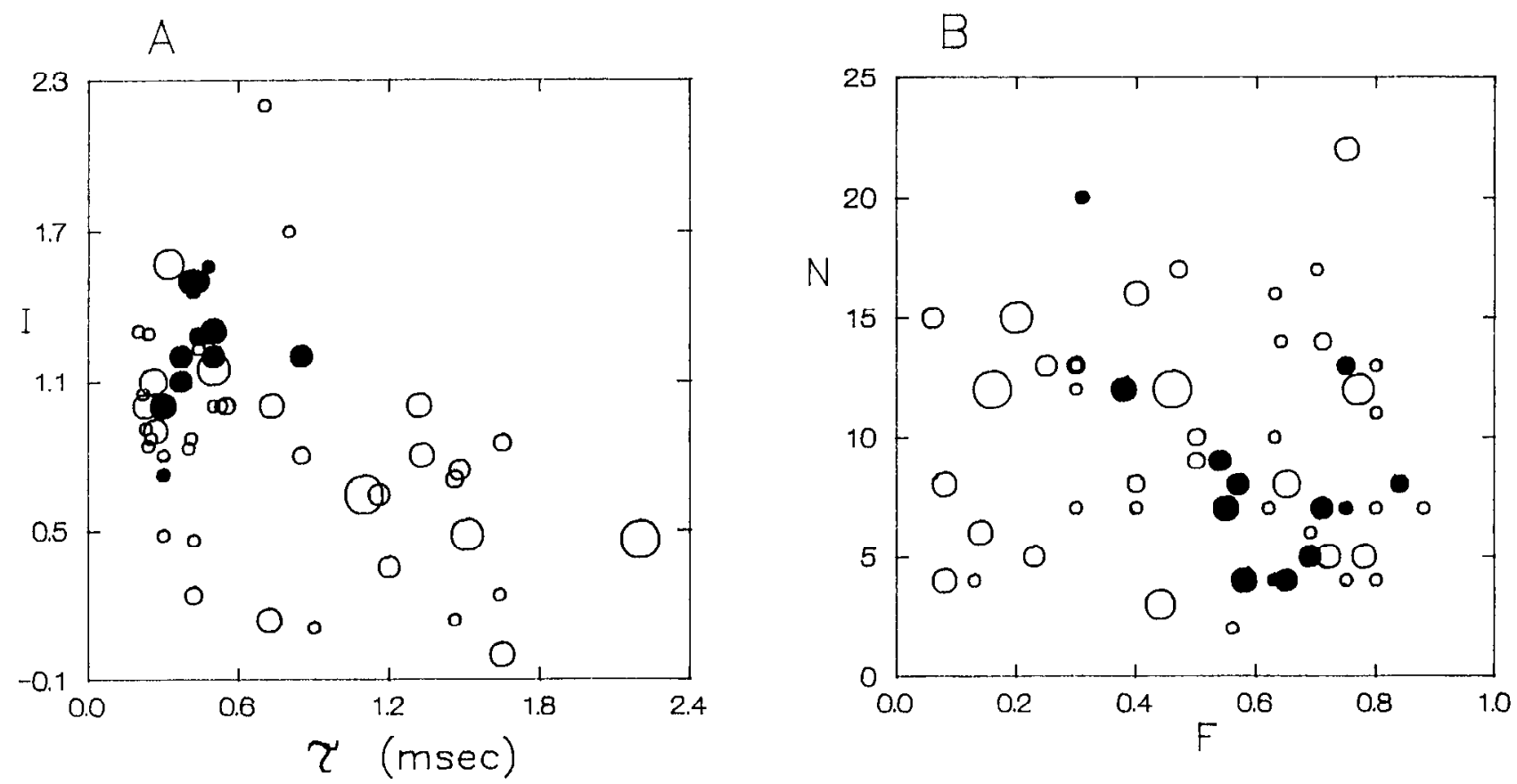

Figure 12. Comparison of kinetic parameters of muscle Ca channels $(0)$ to those of neuronal Ca channels $(O)$. Data for 13 muscle Ca channels are plotted. The area of each circle is proportional to the number of depolarizations studied. $A$, Dot plot of $I$ and $\tau$-values. Neuronal data are the same as in Figure $10 B$. One muscle channel had an $I$ value too large to appear on this plot $(I=4.0, \tau=0.58)$. B, Dot plot of $N$ and $F$ values. Neuronal data are the same as in Figure $4 C$.

by their conductance or voltage dependence of activation. The voltage dependence of activation was only measured carefully for a few channels (Fig. $2 B$ ) because it required a long-lived patch and because there was no indication from the whole-cell studies that there existed $\mathrm{Ca}$ currents with different activation ranges (Byerly and Leung, 1988). All neuronal Ca channels with longer mean open times have about the same conductance, 12$17 \mathrm{pS}$ (Figs. 8B, 9B). The conductances of neuronal Ca channels with shorter mean open times are not well enough determined to distinguish if any have different conductances.

Neuronal $\mathrm{Ca}$ channels are distinguished by their mean open time $(\tau)$, fraction of depolarizations with openings $(F)$, and inactivation $(I)$. Are the channels with different $\tau, F$, and $I$ values truly different, or would they exhibit similar parameters if recorded longer? To answer this question, we divided the data from long-lived patches (studies with 64-160 depolarizations) into sets of 16 depolarizations (the minimum number of depolarizations accepted for characterizing a channel) and calculated $\tau, F$, and $I$ for each set. Although the variation in these parameters for one channel was large (especially for $I$ ), it was much less than the variation observed between patches (Figs. $4,6,10)$. Thus, neuronal $\mathrm{Ca}$ channels do differ in properties that last for at least as long as 160 depolarizations (about 15 $\mathrm{min}$ ). The dot plots of these parameters do not exhibit any clear clustering, as might be expected for discrete types of Ca channels. However, given the large variation in the $\tau, F$, and $I$ values measured from one channel between successive sets of $16 \mathrm{de}-$ polarizations, the data are not inconsistent with the existence of discrete types of channels, especially if there are several types. The demonstration that HoTX blocks noninactivating Ca channels with larger $F$ values, but not the inactivating $\mathrm{Ca}$ channels with smaller $F$ values, lends support to the hypothesis that there are at least two discrete types of Ca channels in Drosophila embryonic neurons. Alternatively, some of the differences in neuronal $\mathrm{Ca}$ channels may result from longer-term internal modulation. It will be interesting to determine if activation of

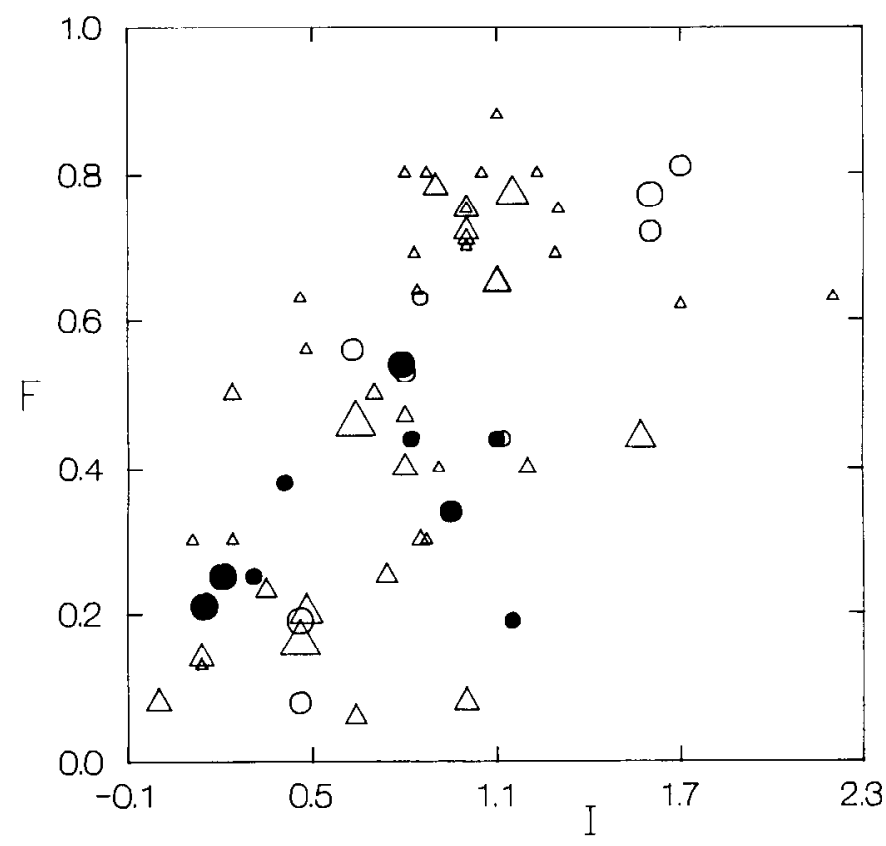

Figure 13. Comparison of $F$ and $I$ values for nine neuronal Ca channels recorded in the presence of HoTX $(\mathbf{O})$ to those of neuronal Ca channels recorded in the absence of toxin (open symbols). The control data are both from the original 42 channels studied $(\triangle)$ and for nine channels recorded from toxin-free cells on the days of the HoTX studies $(O)$. The area of the symbols is proportional to the number of depolarizations studied; the smallest circles and triangles represent 16 depolarizations. 
neuronal kinases can shift the population of Ca channels to larger or smaller values of $\tau, F$, or $I$.

Drosophila muscle $\mathrm{Ca}$ channels are distinct from neuronal $\mathrm{Ca}$ channels. The muscle $\mathrm{Ca}$ channels are much more homogeneous as a class. They never show inactivation during a $90 \mathrm{msec} \mathrm{de-}$ polarization, have intermediate values for mean open times, and open during a majority of depolarizations (Fig. 12). In these properties, the muscle $\mathrm{Ca}$ channels are similar to the HoTXsensitive channels of neurons. Although we have not yet tested HoTX on the Ca current of embryonic muscle cells, HoTX does not block the inward current of pupal flight muscle (Bowers et al., 1987).

The Ca channels of Drosophila embryonic neurons and muscle are similar to most $\mathrm{Ca}$ channels previously studied in that they have rapid kinetics and small conductance. When compared to the Ca channels of vertebrate neurons (Fox et al., 1987), the Drosophila Ca channels are most like the N-type. They have similar conductance and kinetics and are insensitive to dihydropyridines (Byerly and Leung, 1988). However, vertebrate $\mathrm{N}$-type channels are blocked by $\omega$-conotoxin, while Drosophila $\mathrm{Ca}$ channels are not (McCleskey et al., 1987). The different types of Ca channels in vertebrates are distinguished by single-channel conductance and voltage dependence of activation and steadystate inactivation. These properties do not distinguish Drosophila Ca channels. In molluscan neurons, all Ca channels were found to have similar voltage dependence of activation. Although Aplysia bag cell neurons had low-conductance (12 pS) channels and high-conductance ( $24 \mathrm{pS})$ channels, both types activated with the same voltage dependence and had similar kinetics (Strong et al., 1987). The high-conductance channel was activated by stimulation of protein kinase $C$ and was not present in control bag cells. Since these conductances were measured with $185 \mathrm{~mm} \mathrm{Ba}^{2+}$, it is difficult to compare them to the Drosophila and vertebrate $C a$ channel conductances, which are measured with 100 and $110 \mathrm{~mm} \mathrm{Ba}^{2+}$. The Ca channel of Helix neurons had a maximum slope conductance of $7 \mathrm{pS}$ with 40 mM $\mathrm{Ca}^{2}+$ and a mean open time near $1 \mathrm{msec}$, as do most Ca channels (Lux and Brown, 1984).

The Ca channels of Drosophila embryonic neurons and muscle show almost no similarity to the multiple types of Ca channels found in Drosophila brain membranes by Pelzer et al. (1989). These brain $\mathrm{Ca}$ channels are reconstituted in bilayers and studied with $90 \mathrm{mM} \mathrm{Ba}{ }^{2+}$ on both sides of the bilayer and at a maintained potential of $+50 \mathrm{mV}$. The Ca channels of embryonic nerve and muscle become irreversibly inactivated when depolarized for more than a few seconds. Also, the reconstituted brain channels have very long open times, often hundreds of milliseconds, in contrast to the millisecond time scale of the openings of embryonic $\mathrm{Ca}$ channels. Eight distinct $\mathrm{Co}^{2+}-$ sensitive, $\mathrm{Ba}^{2+}$-conducting channels were found in the brain membranes; one channel with a unitary conductance of $13 \mathrm{pS}$ was very sensitive to phenylalkylamines ( $1 \mathrm{~nm}$ ). However, the block by phenylalkylamines was highly voltage dependent, being lost when the membrane was held at even small negative values $(-40 \mathrm{mV})$. The Ca currents of embryonic neurons are insensitive to phenylalkylamines (Byerly and Leung, 1988), but these $\mathrm{Ca}$ currents can only be maintained when the cells are held at potentials more negative than $-40 \mathrm{mV}$. Thus, it is difficult to identify the embryonic Ca channels we have studied with any of those found by Pelzer et al. (1989). There is considerable evidence suggesting that $\mathrm{Ca}$ channels may have quite different properties when studied after reconstitution in bilayers than when studied in situ. Also, it is possible that brain Ca channels come from cells other than neurons or that adult $\mathrm{Ca}$ channels are quite different from embryonic channels.

In characterizing the single-channel properties of the Ca channels in Drosophila embryonic neurons and muscle cells, we have found considerable diversity between channels based on biophysical and pharmacological properties. Our attention now turns to the origins of this diversity. The extent to which intracellular modulation (phosphorylation, $\left[\mathrm{Ca}^{2+}\right]_{i}$, etc.) is involved can be pursued by standard biophysical studies. However, the ultimate identification of the origin of the $\mathrm{Ca}$ channel diversity will require progress in isolating the Drosophila $\mathrm{Ca}$ channel gene(s).

\section{References}

Baker K, Salkoff L (1990) The Drosophila Shaker gene codes for a distinctive $\mathrm{K}^{+}$current in a subset of neurons. Neuron 2:129-140.

Bowers CW, Philips HS, Lee P, Jan YN, Jan LY (1987) Identification and purification of an irreversible presynaptic neurotoxin from the venom of the spider Hololena curta. Proc Natl Acad Sci USA 84: 3506-3510.

Byerly L, Hagiwara S (1988) Calcium channel diversity. In: Calcium and ion channel modulation (Grinnell AD, Armstrong DL, Jackson MB, eds), pp 3-8. New York: Plenum.

Byerly L, Leung H-T (1988) Ionic currents of Drosophila neurons in embryonic cultures. J Neurosci 8:4379-4393.

Corey DP, Stevens CF (1983) Science and technology of patch recording electrodes. In: Single channel recording (Sakman B, Neher E, eds), pp 53-68. New York: Plenum.

Deitmer IW (1984) Evidence for two voltage-dependent calcium currents in membrane of the ciliate Stylonychia. J Physiol (Lond) 355: $137-159$.

Fox AP, Krasne S (1984) Two calcium currents in Neanthes arenaceodentatus egg cell membranes. J Physiol (Lond) 356:491-505.

Fox AP, Nowycky MC, Tsien RW (1987) Single-channel recordings of three types of calcium channels in chick sensory neurons. J Physiol (Lond) 394:173-200.

Hagiwara S, Byerly L (1981) Calcium channel. Annu Rev Neurosci 4:69-125.

Hagiwara S, Ozawa S, Sand O (1975) Voltage clamp analysis of two inward current mechanisms in the egg cell membrane of a starfish. J Gen Physiol 65:617-644.

Hamill OP, Marty A, Neher E, Sakmann B, Sigworth FJ (1981) Improved patch-clamp techniques for high-resolution current recording from cells and cell-free membrane patches. Pfluegers Arch 391:85100.

Haydon PG, Man-Son-Hing H (1988) Low- and high-voltage-activated calcium currents: their relationship to the site of neurotransmitter release in an identified neuron of Helisoma. Neuron 1:919927

Iverson LE, Tanouye MA, Lester HA, Davidson N, Rudy B (1988) A-type potassium channels expressed from Shaker locus cDNA. Proc Natl Acad Sci USA 85:5723-5727.

Lansman JB, Hess P, Tsien RW (1986) Blockade of current through single calcium channels by $\mathrm{Cd}^{2+}, \mathrm{Mg}^{2+}$, and $\mathrm{Ca}^{2+}$. J Gen Physiol 88: 321-347.

Leung HT, Branton WD, Phillips HS, Jan L, Byerly L (1989) Spider toxins selectively block calcium currents in Drosophila. Neuron 3: 767-772.

Lux HD, Brown AM (1984) Patch and whole cell calcium currents recorded simultaneously in snail neurons. J Gen Physiol 83:727-750.

McCleskey EW, Fox AP, Feldman D, Tsien RW (1986) Different types of calcium channcls. J Exp Biol 124:177-190.

McCleskey EW, Fox AP, Feldman DH, Cruz LJ, Olivera BM, Tsien RW, Yoshikami D (1987) $\omega$-Conotoxin: direct and persistent blockade of specific types of calcium channels in neurons but not muscle. Proc Natl Acad Sci USA 84:4327-4331.

Mikami A, Imoto $\mathrm{K}$, Tanabe $\mathrm{T}$, Niidome $\mathrm{T}$, Mori $\mathrm{Y}$, Takeshima $\mathrm{Y}$ Narumiya S, Numa S (1989) Primary structure and functional expression of the cardiac dihydropyridine-sensitive calcium channels. Nature 340:230-233. 
Miller RJ (1987) Multiple calcium channels and neuronal function. Science 235:46-52.

Mironov SL, Tepikin AV, Grishchenko AV (1984) Two calcium currents in the somatic membrane of mollusc neurons (in Russian). Neirofiziologiia 17:627-633.

Pelzer S, Barhanin J, Pauron D, Trautwcin W, Lazdunski M, Pclzer D (1989) Diversity and novel pharmacological properties of $\mathrm{Ca}^{2+}$ channels in Drosophila brain membranes. EMBO J 8:2365-2371.

Salvaterra PM, Bournias-Verdiabasis N, Nair T, Hou G, Lieu C (1987) In vitro neuronal differentiation of Drosophila embryo cells. J Neurosci 7:10-22.

Solc CK, Zagotta WN, Aldrich RW (1987) Single channel and genetic analyses reveal two distinct A-type potassium channels in Drosophila. Science 236:1094-1098.
Strong JA, Fox AP, Tsien RW, Kaczmarek LK (1987) Stimulation of protein kinase $C$ recruits covert calcium channels in Aplysia bag cell neurons. Nature 325:714-717.

Tanabe T, Takeshima H, Mikami A, Flockerzi V, Takahashi H, Kangawa K, Kojima M, Matsuo H, Hirose T, Numa S (1987) Primary structure of the receptor for calcium channel blockers from skeletal muscle. Nature 328:313-318.

Timpe LC, Schwarz TL, Tempel BL, Papazian DM, Jan YN, Jan LY (1988) Expression of functional potassium channels from Shaker cDNA in Xenopus oocytes. Nature 331:143-145. 